\title{
Pengembangan Petunjuk Praktikum Bioteknologi Berbasis Guided Inquiry untuk Peserta Didik SMA di Kabupaten Sumbawa Barat
}

\author{
Sahratullah $^{1}$, Fitri Rahmawati ${ }^{2}$ \\ ${ }^{12}$ Dosen Program Studi Pendidikan Biologi, FKIP, Universitas Cordova \\ Email: 10fitri.rahma@gmail.com
}

\begin{abstract}
Abstrak
Penelitian ini bertujuan untuk mengembangkan petunjuk praktikum berbasis guided inquiry untuk peserta didik SMA di Kabupaten Sumbawa Barat. Penelitian pengembangan ini menggunakan model 4D yang dibatasi sampai tahapan 3D (Develop) yaitu proses validasi ahli (konstruk dan isi) oleh dua validator dan uji keterbacaan oleh peserta didik agar hasil pengembangan dapat diterapkan lebih lanjut dalam proses pembelajaran. Hasil penelitian menunjukkan hasil validasi ahli dari dua validator adalah "sangat valid" dengan nilai rerata skor 3,35 dan persentase sebesar $\mathbf{8 8 , 7 5 \%}$ dan kriteria "sangat baik". Serta hasil yang menunjukkan nilai persentase sebesar 80,47\% dan kriteria "mudah" untuk uji keterbacaan oleh 24 sampel peserta didik kelas XII IPA 1 SMAN 1 Jereweh. Sehingga petunjuk praktikum bioteknologi berbasis guided inquiry dapat diimplementasikan dalam proses pembelajaran untuk peserta didik SMA di Kabupaten Sumbawa Barat.
\end{abstract}

Kata kunci: Pengembangan, Petunjuk Praktikum, Guided Inquiry, Kabupaten Sumbawa Barat.

\section{PENDAHULUAN}

Proses pengubahan sikap dan perilaku melalui upaya pengajaran dan pelatihan baik itu perorang atau sekelompok orang dalam usaha untuk mendewasakan manusia disebut pendidikan (Muhibbin, 2009) ${ }^{[1]}$. Pendidikan diharapkan mampu mendukung pembangunan di masa mendatang dengan mengembangkan potensi peserta didik untuk memecahkan masalah (Trianto, 2010) ${ }^{[2]}$.

Potensi peserta didik untuk memecahkan masalah dapat dikembangkan melalui model pembelajaran yang tepat. Model pembelajaran inkuiri terbimbing (guided inquiry) merupakan model pembelajaran yang sesuai untuk mengembangkan keterampilan intelektual dan keterampilan keterampilan lainnya, seperti mengajukan pertanyaan dan menemukan (mencari) jawaban yang berasal dari keingintahuan mereka (Tangkas, 2012) ${ }^{[3]}$. Tahapan pembelajaran guided inquiry meliputi beberapa fase diantaranya adalah (1) Perumusan masalah. Pada fase ini guru membimbing peserta didik melakukan kegiatan merumuskan masalah dan membagi

Penemuan terbimbing (guided inquiry) yang dilakukan oleh peserta didik dapat menggunakan perangkat pembelajaran berupa petunjuk praktikum. Perangkat pembelajaran peserta didik ke dalam beberapa kelompok yang heterogen. (2) Membuat hipotesis. Pada fase ini guru meminta peserta didik mengajukan jawaban sementara tentang masalah sebelumnya, serta membimbing peserta didik dalam menentukan hipotesis. (3) Merancang percobaan. Pada fase ini guru memberikan kesempatan pada peserta didik untuk menentukan langkah-langkah percobaan (sesuai dengan hipotesis) yang akan dilakukan. Selain itu guru juga membimbing peserta didik dalam menentukan langkah-langkah percobaan. (4) Melakukan percobaan untuk memperoleh data. Pada fase ini guru membimbing peserta didik mendapatkan data melalui percobaan dan pengamatan langsung. (5) Mengumpulkan dan menganalisis data. Pada fase ini guru memberikan kesempatan kepada tiap kelompok untuk mengumpulkan dan menganalisis data hasil percobaan. (6) Membuat kesimpulan. Pada fase ini guru membimbing peserta didik dalam membuat kesimpulan berdasarkan data yang telah dianalisis (Nuryani dan Rustaman, 2005) ${ }^{[4]}$.

yang digunakan harus sesuai dengan model pembelajaran guided inquiry melalui proses pengembangan. Menurut Thiagarajan, dkk $(1974)^{[5]}$ model pengembangan 4D terdiri dari 
beberapa tahapan yaitu: (1) Pendefinisian (Define). Pada tahap ini proses yang dilakukan adalah mendefinisikan serta menetapkan apa saja syarat dalam pembelajaran. (2) Perancangan (Design). Pada tahap ini proses yang dilakukan adalah merancang perangkat pembelajaran diantaranya silabus, RPP, dan petunjuk praktikum bioteknologi berbasis guided inquiry. Selain perangkat pembelajaran, pada tahap ini juga merancang instrumen penelitian diantaranya adalah soal pre-tes dan post-tes, angket validasi konstruk dan isi petunjuk praktikum bioteknologi berbasis guided inquiry, dan angket validasi keterbacaan petunjuk praktikum bioteknologi berbasis guided inquiry. (3) Pengembangan (Develop). Pada tahap ini proses yang dilakukan adalah tahapan untuk menghasilkan produk pengembangan melalui dua langkah yaitu penilaian ahli (dua validator) yang diikuti dengan revisi serta uji keterbacaan petunjuk praktikum oleh peserta didik. (4) Penyebaran (Disseminate). Pada tahap ini proses yang dilakukan adalah penyebaran dan penerapan perangkat pembelajaran dan instrumen penelitian.

Petunjuk praktikum dapat didefinisikan sebagai pedoman pelaksanaan praktikum yang berisi tata cara persiapan, pelaksanaan analisis data dan pelaporan (Purnamasari, 2012) $^{[6]}$. Selain itu menurut Farikhayati (2009) ${ }^{[7]}$ petunjuk praktikum berisi judul-judul percobaan, langkah kerja, lembar pengamatan, serta pertanyaan-pertanyaan yang menggugah rasa ingin tahu serta pengetahuan peserta didik.

Petunjuk praktikum bioteknologi yang dikembangkan pada penelitain ini mengacu pada hasil pengujian organoleptik tepe singkong (Sahratullah, dkk 2017) ${ }^{[8]}$. Model pembelajaran yang dipilih agar bisa menuntun peserta didik dalam melakukan kegiatan praktikum adalah model pembelajaran inkuiri (Al Muhajir, 2015) ${ }^{[9]}$. Petunjuk praktikum yang dikembangkan melalui proses pengembangan yang mengacu pada tahapan pengembangan $3 \mathrm{D}$ yaitu tahapan validasi ahli (konstruk dan isi) oleh dua validator dan uji keterbacaan oleh peserta didik agar hasil pengembangan dapat diterapkan lebih lanjut dalam proses pembelajaran. Penelitian ini bertujuan untuk mengembangkan petunjuk praktikum bioteknologi berbasis guided inquiry untuk peserta didik SMA di Kabupaten Sumbawa Barat.

\section{METODE PENELITIAN}

Penelitian yang kami lakukan merupakan penelitian pengembangan yang menggunakan model pengembangan 4D dari Thiagarajan $(1974)^{[5]}$. Pada penelitian ini tahapan pengembangannya kami batasi sampai tahapan 3D yaitu tahap Pengembangan (Develop) dapat dilihat pada Gambar 1.

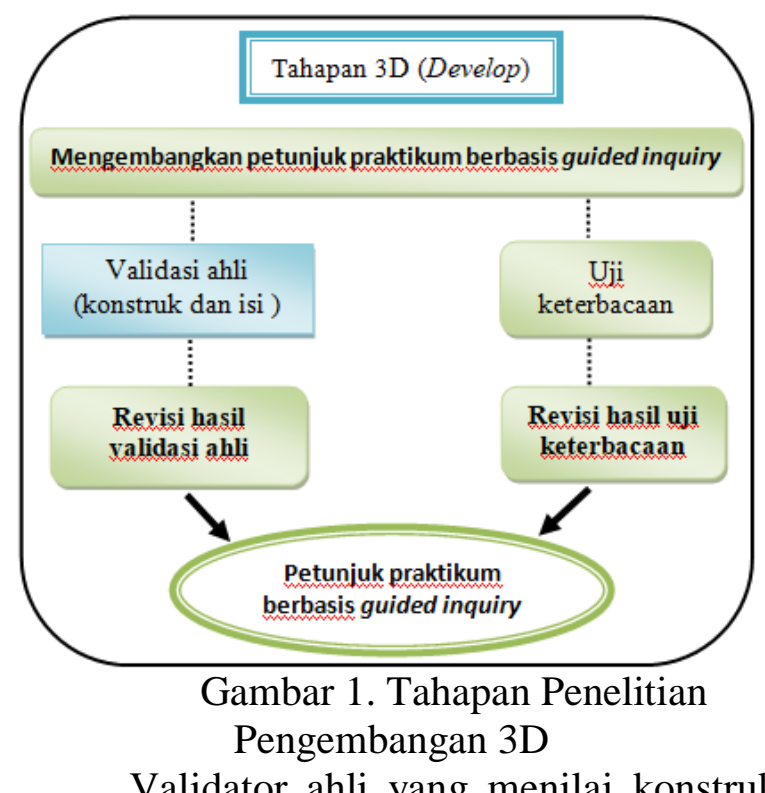

dan isi petunjuk praktikum bioteknologi berbasis guided inquiry adalah Dosen Program Studi Pendidikan Biologi Universitas Cordova (Rizka Donny Agung Saputra, M. Pd dan Dewi Seprianingsih, M.Pd). Sampel penelitiannya adalah 24 peserta didik kelas XII IPA 1 SMAN 1 Jereweh. Instrumen yang digunakan untuk mengumpulkan data adalah lembar validasi petunjuk praktikum bioteknologi berbasis guided inquiry oleh dua validator ahli dan lembar uji keterbacaan petunjuk praktikum bioteknologi berbasis guided inquiry oleh peserta didik. Hasil validasi ahli oleh dua validator serta hasil uji keterbacaan oleh peserta didik selanjutnya akan dianalisis menggunakan teknik analisis rerata skor dengan kriteria kevalidan berdasarkan rerata skor oleh Vendiktama, dkk (2018) ${ }^{[10]}$ serta kriteria persentase hasil validasi dari 
Fajarianingtyas dan Hidayat (2019) ${ }^{[11]}$ dapat dilihat pada Tabel 1 dan Tabel 2.

Tabel 1. Kriteria kevalidan petunjuk praktikum berbasis guided inquiry

\begin{tabular}{cc}
\hline Rerata skor & Kriteria penilaian \\
\hline $3,50-4,00$ & Sangat valid \\
\hline $2,50-3,49$ & Valid \\
\hline $1,50-2,49$ & Tidak valid \\
\hline $1,00-1,49$ & Sangat tidak valid \\
\hline
\end{tabular}

Persentase (\%)

$=\frac{\text { jumlah (jawaban } \times \text { bobot setiap pilihan })}{\mathrm{N} \times \text { bobot tertinggi }} \times 100 \%$

Tabel 2. Kriteria hasil validasi konstruk dan isi petunjuk praktikum berbasis guided inquiry

\begin{tabular}{ccc}
$\begin{array}{c}\text { Tingkat } \\
\text { pencapaian } \\
(\%)\end{array}$ & Kriteria & Keterangan \\
\hline$>80$ & $\begin{array}{c}\text { Sangat } \\
\text { baik }\end{array}$ & $\begin{array}{c}\text { Tidak perlu } \\
\text { direvisi }\end{array}$ \\
\hline $70-79$ & Baik & $\begin{array}{c}\text { Tidak perlu } \\
\text { direvisi }\end{array}$ \\
\hline $60-69$ & Cukup & Direvisi \\
\hline $50-59$ & Kurang & Direvisi \\
\hline$<50$ & $\begin{array}{c}\text { Sangat } \\
\text { kurang }\end{array}$ & Direvisi \\
\hline
\end{tabular}

Hasil penilaian keterbacaan oleh peserta didik selanjutnya akan dianalisis dengan menggunakan kriteria validasi dari Fajarianingtyas dan Hidayat, (2019) ${ }^{[11]}$ dapat dilihat pada Tabel 3.

Tabel 3. Kriteria hasil validasi keterbacaan petunjuk praktikum berbasis guided inquiry

\begin{tabular}{cc}
\hline $\begin{array}{c}\text { Tingkat } \\
\text { pencapaian }(\%)\end{array}$ & Kriteria \\
\hline$>60$ & Mudah \\
\hline $41-60$ & Sedang \\
\hline$<40$ & Sukar \\
\hline
\end{tabular}

Penelitian yang kami lakukan menghasilkan dua produk yaitu petunjuk praktikum bioteknologi berbasis guided inquiry untuk SMA kelas XII semester 2 yang digunakan oleh peserta didik, serta petunjuk praktikum bioteknologi berbasis guided inquiry untuk SMA kelas XII semester 2 yang digunakan oleh guru. Pada artikel jurnal ini kami akan menyampaikan hasil penelitian dan pengembangan petunjuk praktikum bioteknologi berbasis guided inquiry untuk SMA kelas XII semester 2 yang digunakan oleh peserta didik saja. Bagian sampul depan dan belakang petunjuk praktikum bioteknologi berbasis guided inquiry untuk peserta didik dapat dilihat pada Gambar 2.

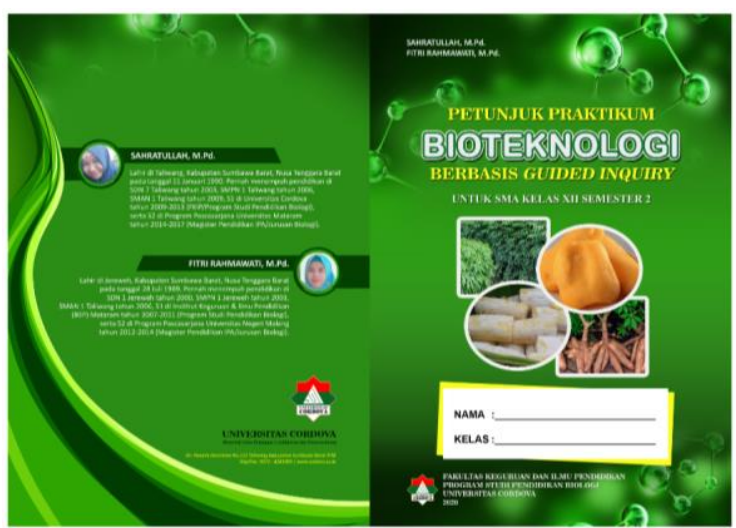

Gambar 2. Sampul depan dan

belakang praktikum bioteknologi berbasis guided inquiry untuk peserta didik

Hasil validasi oleh dua validator ahli untuk aspek konstruk dan isi petunjuk praktikum bioteknologi berbasis guided inquiry untuk peserta didik dapat dilihat pada Tabel 4. Komentar, saran dan masukan yang diberikan oleh kedua validator adalah perlu ditambahkan tata tertib pada bagian petunjuk pelaksanaan praktikum. Pertanyaan pada petunjuk praktikum harus sesuai dengan ranah kognitif pada peserta didik SMA yaitu pada ranah C3 atau C4 untuk skala praktikum.

Tabel 4. Hasil validasi ahli petunjuk praktikum berbasis guided inquiry untuk peserta didik 
Terakreditasi Peringkat 4 (No. SK: 36/E/KPT/2019)

\begin{tabular}{lccc}
\hline Aspek yang dinilai & Rerata skor & $\%$ & Kriteria \\
\hline Kejelasan gambar yang ditampilkan & 4,0 & 10 & Sangat valid \\
\hline Warna pada bagian cover & 4,0 & 10 & Sangat valid \\
\hline Ukuran gambar yang ditampilkan & 4,0 & 10 & Sangat valid \\
\hline Makna gambar yang ditampilkan & 3,5 & 8,75 & Sangat valid \\
\hline Petunjuk pelaksanaan praktikum & 3,0 & 7,5 & Valid \\
\hline Penjabaran referensi/literatur/teori & 3,5 & 8,75 & Sangat valid \\
\hline Tahapan cara kerja praktikum & 3,0 & 7,5 & Valid \\
\hline Kalimat pada petunjuk praktikum & 3,0 & 7,5 & Valid \\
\hline Redaksi kalimat pada petunjuk praktikum & 4,0 & 10 & Sangat valid \\
\hline Makna kalimat pada petunjuk praktikum & 3,5 & 8,75 & Sangat valid \\
\hline Rerata skor seluruh aspek & $\mathbf{3 , 5 5}$ & $\mathbf{8 8 , 7 5}$ & Sangat baik \\
\hline
\end{tabular}

Hasil uji keterbacaan petunjuk praktikum bioteknologi berbasis guided inquiry oleh peserta didik dapat dilihat pada Tabel 5. Komentar, saran dan masukan yang diperoleh dari peserta didik beragam. Diantaranya adalah tidak dicantumkan arti dari istilah asing, materi pada petunjuk praktikum perlu diperbanyak lagi sesuai dengan peta konsep yang ada, perlunya penjelasan lebih lanjut mengenai gambar yang ditampilkan, serta cakupan pengguna buku perlu diperluas. Adanya format pembuatan laporan praktikum dapat membantu peserta didik dalam penyusunan laporan praktikum. Diharapkan dengan adanya petunjuk praktikum bioteknologi berbasis guided inquiry untuk peserta didik dapat meningkatkan aspek sosial (afektif), aspek pengetahuan (kognitif) dan aspek keterampilan (psikomotorik).

Tabel 5. Hasil uji keterbacaan petunjuk praktikum berbasis guided inquiry untuk peserta didik

\begin{tabular}{|c|c|c|c|}
\hline Sampel & $\begin{array}{c}\text { Rerata skor } \\
\text { seluruh } \\
\text { aspek }\end{array}$ & \% & Kriteria \\
\hline 1 & 73 & 76,04 & Mudah \\
\hline 2 & 86 & 89,58 & Mudah \\
\hline 3 & 63 & 65,63 & Mudah \\
\hline 4 & 78 & 81,25 & Mudah \\
\hline 5 & 91 & 94,79 & Mudah \\
\hline 6 & 77 & 80,21 & Mudah \\
\hline 7 & 76 & 79,17 & Mudah \\
\hline 8 & 70 & 72,92 & Mudah \\
\hline 9 & 89 & 92,71 & Mudah \\
\hline 10 & 71 & 73,96 & Mudah \\
\hline 11 & 76 & 79,17 & Mudah \\
\hline 12 & 73 & 76,04 & Mudah \\
\hline 13 & 79 & 82,29 & Mudah \\
\hline 14 & 80 & 83,33 & Mudah \\
\hline 15 & 79 & 82,29 & Mudah \\
\hline
\end{tabular}

\begin{tabular}{|c|c|c|c|}
\hline 16 & 80 & 83,33 & Mudah \\
\hline 17 & 80 & 83,33 & Mudah \\
\hline 18 & 79 & 82,29 & Mudah \\
\hline 19 & 67 & 69,79 & Mudah \\
\hline 20 & 79 & 82,29 & Mudah \\
\hline 21 & 79 & 82,29 & Mudah \\
\hline 22 & 79 & 82,29 & Mudah \\
\hline 23 & 79 & 82,29 & Mudah \\
\hline 24 & 71 & 73,96 & Mudah \\
\hline $\begin{array}{c}\text { Rerata } \\
\text { skor }\end{array}$ & $\mathbf{7 7 , 2 5}$ & $\mathbf{8 0 , 4 7}$ & Mudah \\
\hline
\end{tabular}

Pengembangan petunjuk praktikum bioteknologi berbasis guided inquiry untuk peserta didik ini menunjukkan hasil yang memuaskan. Diantaranya adalah hasil validasi ahli dari dua validator adalah "sangat valid" dengan nilai rerata skor $\mathbf{3 , 3 5}$ dan persentase sebesar 88,75\% dan kriteria "sangat baik". Serta hasil yang menunjukkan nilai persentase sebesar 80,47\% dan kriteria "mudah" untuk uji keterbacaan oleh 24 sampel peserta didik.

Hal ini dapat terjadi karena adanya kegiatan evaluasi dalam proses pengembangan petunjuk praktikum bioteknologi berbasis guided inquiry yang mengacu pada model pengembangan ADDIE oleh Branch (2009) ${ }^{[12]}$. Tahapan pengembangan-evaluasi yang kami lakukan adalah proses validasi ahli tahap pertama dan kedua dapat dilihat pada Gambar 3.

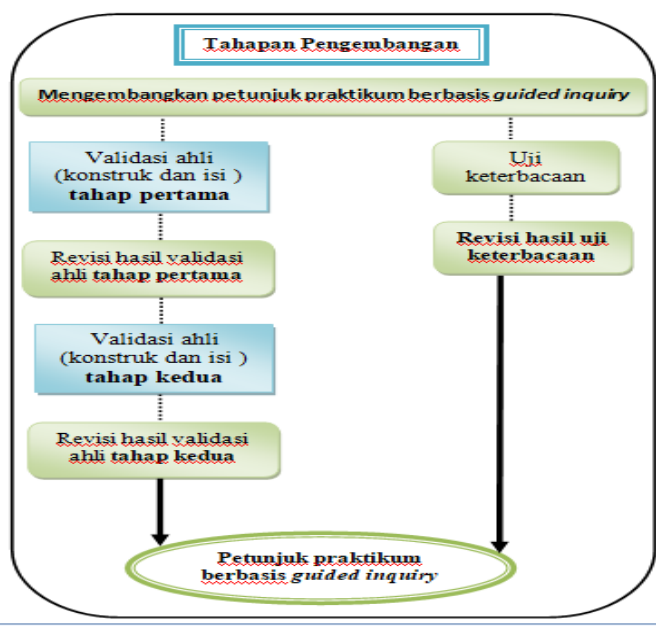

Gambar 3. Tahapan Pengembangan Petunjuk Praktikum Berbasis Guided Inquiry untuk peserta didik

Penelitian dan pengembangan ini menghasilkan produk berupa petunjuk praktikum bioteknologi berbasi guided inquiry 
yang disesuaikan dengan sintak pembelajaran Guided Inquiry oleh Nuryani dan Rustaman $(2005)^{[4]}$. Adapun bagian dari petunjuk praktikum bioteknologi berbasi guided inquiry terdiri dari bagian Sampul Depan, Kata Pengantar, Daftar Isi, Petunjuk Pelaksanaan Praktikum, KI, KD, Indikator Pencapaian Kompetensi, Peta Konsep, Lembar Kerja Praktikum, Daftar Pustaka dan Lampiran. Isi dari Lembar Kerja Praktikum yaitu dimulai dari judul praktikum, tujuan praktikum, materi bioteknologi dan fermentasi. Sintak pembelajaran guided inquiry terdiri dari perumusan masalah yang diwakili dengan membuat pertanyaan oleh peserta didik. Membuat hipotesis/ jawaban/ dugaan sementara dari pertanyaan yang sebelumnya telah dibuat oleh peserta didik. Merancang percobaan praktikum oleh peserta didik. Melakukan percobaan praktikum yang telah dirancang sebelumnya oleh peserta didik. Mengumpulkan data hasil percobaan praktikum dan menganalisis data. Membuat kesimpulan dari analisis data hasil percobaan praktikum.

Penelitian lain yang mengembangkan perangkat pembelajaran berupa petunjuk praktikum berbasis guided inquiry diantaranya adalah Syafruddin, dkk (2016) ${ }^{[13]}$ yang menunjukkan bahwa karakteristik modul biologi yang dikembangkan diintergrasikan dengan sintak inquiry lesson yaitu observasi, manipulasi, generalisasi, verifikasi dan aplikasi sehingga siswa memperoleh pengalaman belajar dan terlibat secara aktif dalam penemuan konsep. Selain itu kelayakan prototipe modul berbasis inquiry lesson ditunjukkan melalui hasil validasi oleh para ahli berkualifikasi sangat baik, hasil validasi oleh praktisi pendidikan berkualifikasi sangat baik dan uji coba skala kecil oleh siswa berkualifikasi baik. Saran yang ditekankan pada penelitian ini adalah agar modul yang dikembangkan dijadikan sebagai bahan rujukan untuk mengembangkan bahan ajar baik itu oleh guru yang menekankan pada aspek keterampilan, serta dilakukan validasi oleh pihak yang berkompeten agar dapat menghasilkan produk modul yang lebih baik. Diperlukan sarana serta prasarana yang memadai dalam penerapan modul berbasis inquiry lesson pada kegiatan praktikum. Masih perlunya pengujian lebih luas (karena penelitian yang telah dilakukan terbatas pada SMA Negeri 1 Magelang), terutama pada tahapan desiminasi dan implementasi agar dapat menyempurnakan tahapan pengembangan yang telah dilakukan.

Penelitian Putro, dkk (2016) ${ }^{[14]}$ menunjukkan bahwa pengembangan perangkat pembelajaran berupa buku ajar telah memenuhi syarat dengan nilai $98,89 \%$ pada uji kelayakan sajian materi dengan kategori valid dan layak digunakan, uji kelayakan dari ahli media dikategorikan valid dengan nilai sebesar 93,35\% dan kelayakan uji terbatas perorangan mahasiswa dikategorikan valid dengan nilai sebesar $94,7 \%$. Pada penelitian selanjutnya diharapkan agar penggunaan buku ajar hasil pengembangan pada penelitian ini digunakan bersama dengan buku teks yang lain. Sarana dan prasarana diharuskan lengkap dan khusus agar buku ajar berbasis penelitian ini dapat digunakan oleh mahasiswa secara langsung dan mandiri. Serta perlu dilakukan penelitian lebih lanjut untuk melaksanakan kegiatan praktikum bersama dari mata kuliah perkembangan hewan dan mata kuliah bioteknologi sehingga menghasilkan sesuatu yang baru dan dapat diterapkan pada kegiatan praktikum mahasiswa.

Selain penelitian diatas, penelitian yang dilakukan oleh Nahak dan Bulu (2020) ${ }^{[15]}$ menunjukkan bahwa penerapan model pembelajaran inkuiri terbimbing berbantu lembar kerja siswa berbasis saintifik memiliki efektivitas terhadap hasil belajar IPA siswa kelas VI di SDI Bakunase Kupang. Penelitian ini menyarankan agar peneliti yang akan melakukan penelitian yang sejenis agar terlebih dahulu melakukan kajian terhadap perangkat pembelajaran yang telah dibuat sehingga sesuai dengan alokasi waktu, fasilitas pendukung serta karakter siswa yang menjadi sampel penelitian. Penelitian Nurjanah, dkk $(2016)^{[16]}$ menunjukkan bahwa modul biologi berbasis guided inquiry laboratory efektif untuk memberdayakan hasil belajar aspek pengetahuan (kognitif), aspek sosial (afektif) dan aspek keterampilan (psikomotorik). Pada 
penelitian selanjutnya disarankan agar menggunakan modul yang telah dikembangkan pada penelitian ini sebagai salah satu rujukan bagi guru yang membutuhkan keterampilan. Pengembangan modul perlu divalidasi oleh validator yang kompeten agar menghasilkan produk modul yang lebih baik. Kegiatan praktikum menggunakan modul biologi berbasis guided inquiry laboratory harus disesuaikan dengan sarana dan prasarana yang memadai untuk menunjang kegiatan praktikum. Perlunya penyempurnaan tahapan pengembangan pada pengujian modul biologi berbasis guided inquiry laboratory secara luas (desiminasi dan implementasi) bukan hanya terbatas pada satu sekolah yaitu SMA Negeri 1 Magelang. Selain itu modul biologi berbasis guided inquiry laboratory dapat dikembangkan lagi dengan menyesuaikan materi pokok atau pokok bahasan pada siswa SMA kelas X, XI dan XII.

Hal ini sejalan dengan hasil penelitian Arifah, dkk (2014) ${ }^{[17]}$ yang menyatakan bahwa hasil pengamatan observer sebesar $84 \%$ menunjukkan bahwa buku petunjuk praktikum berbasis guided inquiry cukup mengoptimalkan kemampuan hands on mahasiswa. Pada penelitian selanjutnya diharapkan pengembangan buku petunjuk praktikum agar ditambahkan alokasi waktu serta sampel penelitian. Serta hasil penelitian Mislia, dkk (2017) ${ }^{[18]}$ yang menyatakan bahwa hasil analisis kepraktisan petunjuk praktikum sebanyak 85,18\% dari 27 siswa memberikan respon positif terhadap penggunaan petunjuk praktikum biologi materi uji zat makanan dalam memberikan kemudahan terhadap pelaksanaan praktikum serta pemahaman siswa terhadap materi uji zat makanan. Selain itu, hasil analisis keefektifan petunjuk praktikum keseluruhan siswa menunjukkan bahwa penggunaan petunjuk praktikum berbasis inkuiri terbimbing efektif digunakan sebagai panduan pada kegiatan praktikum karena nilai rata-rata gain sebesar 0,63 masuk kategori sedang.

\section{KESIMPULAN}

Kesimpulan penelitian berdasarkan hasil penelitian dan pembahasan adalah petunjuk praktikum bioteknologi berbasis guided inquiry untuk peserta didik dinyatakan "sangat valid" dengan nilai rerata skor $\mathbf{3 , 3 5}$ dan persentase sebesar $\mathbf{8 8 , 7 5 \%}$ dan kriteria "sangat baik". Serta hasil yang menunjukkan nilai persentase sebesar $\mathbf{8 0 , 4 7 \%}$ dan kriteria "mudah" untuk uji keterbacaan oleh peserta didik. Sehingga petunjuk praktikum bioteknologi berbasis guided inquiry dapat diimplementasikan dalam proses pembelajaran untuk peserta didik SMA di Kabupaten Sumbawa Barat.

\section{SARAN}

Saran yang perlu diperhatikan untuk penelitian selanjutnya adalah (1) Menjadikan petunjuk praktikum bioteknologi berbasis guided inquiry sebagai bahan rujukan untuk mengembangkan materi serta metode pembelajaran yang sesuai dengan kemampuan baik itu untuk peserta didik ataupun mahasiswa. (2) Menerapkan petunjuk praktikum bioteknologi berbasis guided inquiry dalam proses pembelajaran agar dapat meningkatkan kemampuan berpikir peserta didik SMA khususnya di Kabupaten Sumbawa Barat. (3) Mengevaluasi hasil penerapan petunjuk praktikum bioteknologi berbasis guided inquiry skala luas (Tahapan 4D yaitu Penyebaran /Disseminate) agar bisa menghasilkan produk petunjuk praktikum yang lebih valid dari sebelumnya. (4) Mengenalkan petunjuk praktikum bioteknologi berbasis guided inquiry melalui forum ilmiah seperti jurnal, prosiding, workshop, seminar lokal/nasional/internasional, atau melalui forum guru seperti MGMP.

\section{UCAPAN TERIMA KASIH}

Artikel ini merupakan bagian dari Penelitian Dosen Pemula dengan judul "Pengembangan Petunjuk Praktikum Berbasis Guided Inquiry untuk Meningkatkan Kemampuan Berpikir Kritis Peserta Didik SMA di Kabupaten Sumbawa Barat". Penelitian ini dibiayai oleh Direktorat Riset dan Pengabdian Masyarakat, Deputi Bidang Penguatan Riset dan Pengembangan, Kementerian Riset dan Teknologi/ Badan 
Riset dan Inovasi Nasional sesuai dengan Kontrak Penelitian Tahun Anggaran 2020.

Terima kasih kami sampaikan kepada semua pihak yang membantu penelitian yang kami laksanakan diantaranya adalah Kementerian Riset dan Teknologi/ Badan Riset dan Inovasi Nasional, Program Studi Pendidikan Biologi, Fakultas Keguruan dan Ilmu Pendidikan Universitas Cordova, LRP2M Universitas Cordova, Bappeda Litbang Kabupaten Sumbawa Barat, SMA Negeri 1 Jereweh, serta semua pihak-pihak yang terlibat dalam penelitian ini.

\section{DAFTAR PUSTAKA}

Muhibbin, S. 2009. Psikologi Belajar. Jakarta: PT Raja Grafindo Persada.

Trianto. 2010. Mendesain Model Pembelajaran Inovatif-Progresif: Konsep Landasan dan Implementasinya pada Kurikulum Tingkat Satuan Pelajaran (KTSP). Jakarta: Kencana Prenada Media Group

Tangkas, I.M. 2012. Pengaruh Implementasi Model Pembelajaran Inkuiri Terbimbing terhadap Kemampuan Pemahaman Konsep dan Keterampilan Proses Sains Peserta Didik Kelas X SMAN 3 Amlapura. Tesis: Program Studi Pendidikan Sains, Pascasarjana Universitas Pendidikan Ganesha.

Nuryani, Y dan Rustaman. 2005. Strategi Belajar Mengajar Biologi. Malang: IKIP Malang.

Thiagarajan, S., Semmel, D.S., dan Semmel, M.I. $\quad 1974 . \quad$ Instruction Development for Training Teacher of Exceptional Children: A Sourcebook. Indiana University Bloomington. Diunduh dari http://file.eric.ed.gov/fulltext/ED090725.pdf pada tanggal 17 Agustus 2019.

Purnamasari, S. 2012. Pengembangan Petunjuk Praktikum Kimia SMA pada Pokok Bahasan Stoikiometri. Skripsi diterbitkan. Semarang: UPI.
Farikhayati. 2009. Pengembangan Buku Petunjuk Kimia untuk SMP/MTs Kelas VII berdasarkan Kurikulum Tingkat Satuan Pendidikan (KTSP). Skripsi diterbitkan. Yogyakarta: Program Studi Pendidikan Kimia Fakultas Sains dan Teknologi Universitas Islam Negeri Sunan Kalijaga.

Sahratullah., Jekti, D.S.D., dan Zulkifli, L. 2017. Pengaruh Konsentrasi Ragi dan Lama Fermentasi terhadap Kadar Air, Glukosa dan Organoleptik pada Tape Singkong. Jurnal Biologi Tropis. Volume 17 Nomor 1 e-ISSN: 2549-7863.

Al Muhajir, M. 2015. Pengembangan Penuntun Praktikum Bioteknologi Kelas XII IPA SMA Negeri 1 Binamu Kabupaten Jeneponto. Jurnal Biotek. Volume 3 (1).

Vendiktama, P.R., Al-Muhdar, M.H.I. dan Suarsini, E. 2018. Pengembangan Modul Biologi Bermuatan Konsep 6M dan Etika Lingkungan Berbasis Model Project Based Learning $(P j B L)$ untuk Siswa SMA. Jurnal Pendidikan. Volume 3 (2). Februari 2018. E-ISSN: 2502-471X. DOAJSHERPA/RoMEO-Google Scholar-IPI.

Fajarianingtyas, D.A., dan Hidayat, J.N. 2019. Validitas Buku Petunjuk Praktikum Biologi Dasar Berbasis Pemecahan Masalah untuk Mahasiswa Pendidikan IPA di Universitas Wiraraja. Lensa (Lentera Sains): Jurnal Pendidikan IPA. Volume 9 (2). November 2019. ISSN: 2301-5071. e-ISSN: 2406-7393.

Branch, R.M. (2009). Instructional Design: The ADDIE Approach. Speingger Science Business Media, LLC.

Syafruddin., Sajidan., dan Sugiyarto. 2016. Pengembangan modul biologi berbasis inquiry lesson pada materi bioteknologi kelas XII SMA Negeri 1 Magelang. Jurnal Inkuiri. 
Volume 5 Nomor 3. ISSN: 22527893.

Putro, S.D.K., Lestari, U., dan Lukiati, B. 2016. Pengembangan buku ajar perkembangan hewan berbasis penelitian metamorfosis ulat sutera Bombyx mori L. Jurnal Pendidikan. Volume 1 Nomor 7. e-ISSN: 2502471X.

Nahak, R.L., dan Bulu, V.R. 2020. Efektivitas model pembelajaran inkuiri terbimbing berbantu lembar kerja siswa berbasis saintifik terhadap hasil belajar siswa. Jurnal Kependidikan. Volume 6 Nomor 2 e-ISSN: 2442-7667 doi: https://doi.org/10.33394/jk.v6i2.23 69

Nurjanah, A.K., Sajidan., dan Karyanto, P. 2016. Pengembangan modul biologi berbasis model guided inquiry laboratory pada materi bioteknologi. Jurnal Inkuiri. Volume 5 Nomor 3. ISSN: 22527893.

Arifah, I., Maftukhin, A., dan Fatmaryanti, S.D. 2014. Pengembangan buku petunjuk praktikum berbasis guided inquiry untuk mengoptimalkan hands on mahasiswa semester II Program Studi Pendidikan Fisika Universitas Muhammadiyah Purworejo Tahun Akademik 2013/2014. Jurnal Radiasi. Volume 5 Nomor 1.

Mislia., Qurbaniah, M., dan Kahar, A.P. 2017. Pengembangan petunjuk praktikum biologi berbasis inkuiri terbimbing pada materi sistem pencernaan. Jurnal Bioeducation. Volume 4 Nomor 1. 